\title{
A questionnaire approach to transitivity in children'
}

RICHARD D. ODOM AND ROBERT C. COON VANDERBILT UNIVERSITY

In the present study 7-year-old children were verbally presented transitivity problems in which the type of relational term was varied. Although the majority of $S$ s indicated the presence of the concept, more correct responses were made on problems employing the same relational term throughout than on problems that used different and opposite terms.

According to Piaget (Flavell, 1963), one manifestation of the child's entry into the period of concrete operations is the ability to make transitive inferences. A transitivity concept is assumed present when one is able to observe, e.g., $A>B, B>C$, and then infer that $A>C$. The inference about a never stated relationship $(A>C)$ is therefore derived from information concerning two separately stated relationships ( $A>B$ and $B>$ C). The concept is of considerable importance in that it is assumed to be an underlying component of measurement procedures.

Most of the recent literature on the development of transitivity evolved from a controversy between Braine $(1959,1964)$ and Smedslund $(1963,1965)$. This controversy focused on the appropriate method for assessing the emergence of the concept at various points in development.

Smedslund's (1963) technique involved presenting two sticks of different sizes in a Mueller-Lyer context so that the longer stick appeared shorter. After $S$ had compared an intermediate sized stick (B) with the Mueller-Lyer sticks ( $A$ and $C$ ), $S$ was asked to judge which was longer, $A$ or $C$. The results of this study indicated the concept to be present in a majority of Ss no earlier than age 8. Braine (1959) trained Ss on the relational concept of length and on a subsequent transitivity test found evidence for the transitivity concept in a majority of Ss as young as 5 . He argued (1964) that Smedslund had been unable to detect the concept in younger Ss because they lacked an understanding of relational terms such as longer than. Braine's point is well taken, but only when the transitive response is absent or occurs at chance frequency, i.e., it is reasonable to assume that appropriate meaning is attached to the relational term if the transitivity response is given to a number of items.

Both of these investigators employed concrete objects, i.e., children observed actual sticks being compared. Smedslund makes a point of referring to concrete as opposed to formal transitivity, which he feels involves making relational inferences from verbally stated, hypothetical premises.
The earliest account of a pure questionnaire approach to assessing the concept concerns items like those on the Burt test (Piaget, 1964, p. 87), e.g., "Edith is fairer than Suzanne; Edith is darker than Lili. Which is the darkest, Edith, Suzanne, or Lili?" According to Piaget, children as old as 13 years give incorrect answers to such items. The difficulty may be due to the use of different and opposite relational terms, which may require additional and distracting steps in the encoding process.

The present study was designed to determine the ability of second grade children to solve verbally presented transitivity problems without the aid of concrete materials. In addition, the effect of type of relational term on transitivity responses was assessed by presenting a term in the problem's question that was either different from or the same as those presented in the previous relational statements of the problem. Method

The Ss were 95 second grade children with a mean CA of 7 years 8 months. An approximately equal number of Ss were from each of three classrooms in a Nashville school serving middle class families.

The stimulus materials consisted of two examples and six problems involving a transitive relationship. The example problems were of the following form: "The yellow line (circle) is longer (larger) than the brown line (circle); the brown line (circle) is longer (larger) than the orange line (circle). Which is longer (larger), the yellow line (circle) or the orange line (circle)?" The six problems followed the same format and contained the same three colors as the example problems, but the objects and the comparison terms differed. For Problems 1 through 6 the object terms were, respectively, chair, house, car, glass, stick, and bicycle, and the comparison terms accompanying the object terms were, more (comfortable), smaller, longer, more (water), taller, and faster. The position of the colors in the relationship statements and of the color of the correct cholce in the question were counterbalanced across problems.

There were three consistent problems $(1,4$, and 6$)$ which contained the same comparison term in the initial statements and question. In the three inconsistent problems the question contained an opposite comparison term from that used in the initial statements, e.g., in Problem 2 the houses were compared with the term smaller in the initial statement and with the term bigger in the question.

Answer sheets were employed, and in a row across 
the top of each sheet were three differently colored rectangles representing the three colors contained in each problem. The rectangles were approximately $3 \mathrm{in}$. apart, and their left and right position was determined by one of three position orders. Along the left margin of the sheet was a column of numbers from 1 to 6 , with a $3 / 4$ in. space between each. Eighteen lines, provided for Ss' answers, were arranged in rows of three to the right of each number and in columns of six below each rectangle.

The experiment was conducted in three separate classrooms. Answer sheets were distributed so that the position order of the colored rectangles was different for adjacent Ss. A female $E$ presented the examples and problems, and two other adults proctored to insure that Ss followed instructions and did not copy.

For the first example, E drew three lines of different heights and colors on the blackboard and then according to the above format stated the relationship between the lines. She then indicated the correct answer and showed Ss how they would be marking their answer sheets. The second example followed the same procedure, but first, Ss were asked to imagine three colored circles of decreasing size and were then presented a question and answer regarding the transitive relation between them. This example was then repeated using a blackboard illustration.

Following the examples, E explained to the Ss that the remaining questions had no pictures and that they would have to think about the correct answers. The Ss were reminded to draw an $X$ under the color that matched the correct answer to each problem. Each problem was presented twice. The Ss were told to listen carefully during the first reading and then to mark their answers after the second reading.

\section{Results and Discussion}

Table 1 presents the percentage of Ss making correct responses on different numbers of questionnaire items. A $\chi^{2}$ goodness of fit test was employed to determine if the distribution of the number of Ss making 0 to 6 correct responses differed from that of a normal distribution. The upper two categories ( 5 and 6 correct items) and the lower two categories (0 and 1) were combined so that the expected frequencies for all categories was greater than 5 . The results of the test indicated that the distribution deviated significantly from a normal distribution $\left(X^{2}=398.5, \mathrm{~d} f=4, \mathrm{p}<.001\right)$. As seen in Table 1 , only $14.8 \%$ of the Ss gave transitivity responses at or below chance frequency, while $85.2 \%$ responded at greater than chance level.

Smedslund (1963) reported that only by the ages of

Table 1. Percentage of Ss Making Zero to Six Correct Responses

\begin{tabular}{ccccccc}
\multicolumn{7}{c}{ Number } \\
0 & 1 & 2 & 3 & 4 & 5 & 6 \\
\hline 0.0 & 0.0 & 5.3 & 9.5 & 10.5 & 38.9 & 35.8
\end{tabular}

Table 2. Percentage of Ss Responding Correctly on Each Problem Problem Number

\begin{tabular}{cccccc}
1 & $2^{*}$ & $3^{*}$ & 4 & $5^{*}$ & 6 \\
\hline 93.7 & 73.7 & 57.9 & 85.3 & 84.2 & 85.3 \\
\hline
\end{tabular}

*Inconsistent problems.

9 and 10 did $85 \%$ of the Ss in his sample meet the transitivity criterion on his Mueller-Lyer task, while the percentage of Ss meeting the criterion in age groups below 8 years did not exceed $30 \%$. Even though Smedslund employed the Mueller-Lyer task in order to prevent Ss from making transitive responses based solely on perceived differences in object length, it may be that the illusion cues were distracting for children below the age of 8 due to the relative instability of the transitivity concept. The results of the present study indicate that with such distracting cues absent, children in the age range of 7 to 8 are quite capable of dealing with verbally presented transitive relationships.

Table 2 presents the percentage of Ss responding correctly on each of the six problems. The results of a $t$ test for correlated measures indicated that the number of correct responses made on the consistent problems $(M=2.64)$ and those made on the inconsistent problems $(M=2.26)$ differed significantly $(t=4.33$, df $=94, \mathrm{p}<.001)$. It is assumed that the additional steps required for reorganizing the relationship between the three items so that it was orderly, e.g., $A>B>C$, was distracting and resulted in more incorrect responses on the inconsistent problems.

It is evident from the results of the present study and earlier work that various task factors affect the manifestation of the transitivity concept at different age levels. The concept is apparently not always evidenced after its emergence. However, with increasing age, greater success on transitivity problems is realized, possibly reflecting either a more stable concept or an increased ability to process distracting information or both.

\section{References}

BRAINE, M. S. The ontogeny of certain logical operations: Piaget's formulation examined by nonverbal methods. Psychol Monogr., 1959, 73 (Whole No. 475).

BRAINE, M. S. Development of a grasp of transitivity of length: A reply to Smedslund. Child Develpm., 1964, 35, 799-810.

FLAVELL, J. H. The developmental psychology of Jean Piaget. New York: Van Nostrand, 1963.

PIAGET, J. Judgement and reasoning in the child. New Jersey: Littlefield, Adams and Co., 1964.

SMEDSLUND, J. The development of concrete transitivity in children. Child Develpm., 1963, 34, 389-405.

SMEDSLUND, J. The development of transitivity of length: A comment on Braine's reply. Child Developm, 1965, 36, 577-580.

Note

${ }^{1}$ This project was supported by grant HD-01654 from the National Institute of Child Health and Human Development. The authors express their appreciation to the staff of Norman Binkley Elementary School for their cooperation during the course of the project. 